\title{
PRIMARY NOCTURNAL ENURESIS IN A PAEDIATRIC PRACTICE IN CROATIA
}

\section{Helena Živić, Health facility Zagreb Center, Croatia helena,strizic@gmail.com}

\section{Background and Aims:}

Bedwetting is the most common childhood complaint and it is important to ask children and their parents about nocturnal incontinence during health visit at 5 years of age.

\section{Aim was to analyze patients with primary nocturnal enuresis (PNE) in our pediatric practice.}

Methods: We collected electronic data of children 5 years of age, descriptive statistical analysis was used.

Results: Out of 100 patients 5 years of age 7 had PNE (7\%), 5 boys, 2 girls. In only 2 cases parents referred the problem themselves during regular health visit, in all other cases only when asked if the child had bedwetting. Two children $(28,6 \%)$ had both enuretic parents, 4 children $(57,1 \%)$ had 1 enuretic parent (father in all cases) and 1 child had no family history of PNE. Pediatric and neurological exam and blood pressure were normal in all children. All patients had normal urin analysis and normal ultrasound of the urinary system. Parents were advised to keep voiding diaries. All patients had nocturnal polyuria. Five patients $(71,4 \%)$ were administered Desmopressin acetate (Minirin 120ug) for 3 months with no relapse. Two patients $(28,6 \%)$ were recommended alarm devices.

Conclusion: It is important to address and treat PNE because if unrecognized the problem worsens and can result in emotional stress. 